\title{
Impact of decitabine on immunohistochemistry expression of the putative tumor suppressor genes FHIT, WWOX, FUS1 and PTEN in clinical tumor samples
}

David J Stewart ${ }^{1 *}$, Maria I Nunez ${ }^{2}$, Jaroslav Jelinek ${ }^{3}$, David Hong ${ }^{2}$, Sanjay Gupta², Marcelo Aldaz ${ }^{4}$, Jean-Pierre Issa ${ }^{3+}$, Razelle Kurzrock ${ }^{5+}$ and Ignacio I Wistuba ${ }^{2+}$

\begin{abstract}
Background: Since tumor suppressor gene function may be lost through hypermethylation, we assessed whether the demethylating agent decitabine could increase tumor suppressor gene expression clinically. For fragile histidine triad (FHIT), WW domain-containing oxidoreductase (WWOX), fused in sarcoma-1 (FUS1) and phosphatase and tensin homolog (PTEN), immunohistochemistry scores from pre- and post-decitabine tumor biopsies (25 patients) were correlated with methylation of the long interspersed nuclear element-1 (LINE-1) repetitive DNA element (as a surrogate for global DNA methylation) and with tumor regression.

Results: With negative staining pre-decitabine $(s c o r e=0)$, the number of patients converting to positive staining post-decitabine was 1 of 1 for FHIT, 3 of 6 for WWOX, 2 of 3 for FUS1 and 1 of 10 for PTEN. In tumors with low pre-decitabine tumor suppressor gene scores $(\leq 150)$, expression was higher post-treatment in 8 of 8 cases for FHIT $(P=0.014)$, 7 of 17 for WWOX ( $P=0.0547), 7$ of 12 for FUS1 $(P=0.0726)$, and 1 of 16 for PTEN $(P=0.2034)$. If FHIT, WWOX and FUS1 were considered together, median pre- versus post-decitabine scores were 60 versus $100(P=0.0002)$. Overall, tumor suppressor gene expression change did not correlate with LINE-1 demethylation, although tumors converting from negative to positive had a median decrease in LINE-1 methylation of 24\%, compared to $6 \%$ in those not converting $(P=0.069$ ). Five of 15 fully evaluable patients had reductions in tumor diameter (range $0.2 \%$ to 33.4\%). Of these, three had simultaneous increases in three tumor suppressor genes (including the two patients with the greatest tumor regression) compared to 2 of 10 with tumor growth $(P=0.25)$.

Conclusions: In tumors with low tumor suppressor gene expression, decitabine may be associated with increased expression of the tumor suppressor genes FHIT, FUS1, and WWOX, but not PTEN.
\end{abstract}

Keywords: Decitabine, FHIT, FUS1, WWOX, PTEN, Tumor suppressor genes, LINE-1 methylation

\section{Background}

Several tumor suppressor genes have now been described, and tumor suppressor gene silencing by mutation, deletion, or hypermethylation [1,2] is an important component of tumorigenesis. Treatment of cell lines or xenograftbearing animals with the demethylating agents decitabine and 5-azacytidine has been reported to increase

\footnotetext{
* Correspondence: dstewart@toh.on.ca

${ }^{\dagger}$ Equal contributors

'University of Ottawa, 501 Smyth Rd, Ottawa, ON K1H 8 L6, Canada

Full list of author information is available at the end of the article
}

expression of a variety of tumor suppressor genes [3-6]. Decitabine may upregulate gene expression through both methylation-dependent and methylation-independent mechanisms $[1,2]$.

Decitabine is active clinically in some hematologic malignancies [7]. Administration of low doses of decitabine daily for multiple successive days may be most effective against hematological malignancies, and is also particularly likely to induce DNA demethylation [7].

In patients with refractory malignancies receiving low dose decitabine on days 1 to $5 \pm$ days 8 to 12 each cycle, 
we biopsied tumors before day 1 and on day 12 of cycle 1 , and found in patient tumors that decitabine decreased methylation of the long interspersed nuclear element-1 (LINE-1) repetitive DNA element (as a surrogate for global DNA methylation) [8], while it increased tumor expression of the copper transport protein-1 (CTR1, a copper/platinum transporter) [8], the Ras homolog gene family member A (RhoA, an endocytosis regulator) [9], and the reduced folate carrier-1 (RFC1, a folate transporter) [9]. In pre-decitabine tumor samples, expression of CTR1 [8] and RhoA [9] was lower and LINE-1 methylation tended to be higher in patients who were $\leq 3$ months versus $>3$ months beyond most recent prior therapy [8], and LINE-1 methylation correlated inversely with expression of CTR1 [8] and RhoA [9].

Based on our observations with CTR1 [8], LINE-1 [8], and RhoA [9], we then investigated whether expression of selected tumor suppressor genes would vary with time from last treatment, with LINE-1 methylation and with decitabine treatment. The tumor suppressor genes assessed were fragile histidine triad (FHIT), WW domain-containing oxidoreductase (WWOX), fused in sarcoma-1 (FUS1) and phosphatase and tensin homolog (PTEN).

FHIT is a proapoptotic tumor suppressor gene that encodes the fragile histidine triad protein (FHIT, also known as bis-(5'-adenosyl) triphosphatase), and FHIT inactivation or loss occurs in many tumor types [10]. Loss of FHIT leads to alterations in the DNA damage response checkpoint, resulting in increased DNA instability [11]. Loss of FHIT expression is commonly associated with hypermethylation of the gene, and frequent FHIT hypermethylation has been reported in hepatocellular carcinomas [12], and in carcinomas of the larynx [13], breast [14], lung [14], cervix [15], vulva [16], and kidney [17]. The demethylating agent decitabine may increase expression of FHIT in cancer cell lines [3].

$W W O X$ is a large gene spanning the chromosomal fragile site 16D [18]. It encodes the protein WW domaincontaining oxidoreductase (WWOX) which may play a role in apoptosis [19], cell metabolism [20], and modulation of the activity of multiple interacting transcription factors [21]. WWOX is generally strongly expressed in various normal tissues [22], but its expression by immunohistochemistry (IHC) is absent or weak in many cancers arising from tissues that generally express WWOX, including cancers of the breast [18], ovary [23], bladder [24], and esophagus [25], and in leukemias [19]. Exposure to carcinogens such as cigarette smoking extract can lead to downregulation of $W W O X$ expression [24]. WWOX downregulation has been noted to occur via promoter methylation in various malignancies [25-27], and decitabine may restore WWOX expression $[3,4]$.

The FUS1 gene (also known as tumor suppressor candidate 2 or TUSC2) is located in the chromosomal 3p21.3 region. In lung cancers and various other malignancies, this chromosomal region is frequently deleted and FUS1/TUSC2 expression is often lost [28]. FUS1 functions as a tumor suppressor gene by inducing apoptosis through activation of the intrinsic mitochondrialdependent and Apaf-1-associated pathways [28]. FUS1/ TUSC 2 may be hypermethylated in cancers of the head and neck, and decitabine may reverse this hypermethylation [29]. In breast cancer cell lines, decitabine increased expression of FUS1/TUSC2 despite lack of gene methylation [30], in keeping with the known ability of decitabine to increase gene expression through both methylation-dependent and methylation-independent mechanisms $[1,2]$.

PTEN functions as a tumor suppressor gene by negatively regulating the Akt pathway, and it is one of the most frequently inactivated tumor suppressor genes in human cancers [31]. PTEN hypermethylation has been reported to be common in several tumor types [32-35]. Demethylating agents have been reported to restore PTEN expression in cell lines with hypermethylated PTEN $[5,6]$. However, PTEN protein expression did not change with decitabine exposure in ovarian cancer cell lines [36], and the role of promoter hypermethylation in silencing PTEN expression is not clear-cut. While the above studies suggested a role for PTEN promoter hypermethylation, several other studies across a range of malignancies have failed to detect significant PTEN promoter methylation [37-40]. It has been noted that the PTENP1 pseudogene (that has $98 \%$ homology with PTEN) is frequently hypermethylated in tumors and cell lines, while PTEN is not, and reports of methylation of PTEN have been attributed by some authors to misinterpretations of hypermethylation of PTENP1 [38].

\section{Results \\ Patient characteristics}

Patient characteristics are presented in more detail in an earlier publication on this patient group [8]. Patient numbers varied slightly between tumor suppressor genes since insufficient biopsy material was available for some assessments. Twenty-five of 31 patients who were initially entered on our decitabine phase I clinical trial [8] had sufficient tissue to permit at least one IHC assessment (either pre- or post-decitabine) of at least one of the four tumor suppressor genes of interest. These 25 patients included 14 males and 11 females, with a median (range) age of 53 (20 to 75 ) years. Tumor types included cancers of the breast (four patients), kidney (three), head and neck (three, including one adenocystic carcinoma), lung (one), stomach (one), and appendix (one), malignant melanomas (four), thymic neoplasms (three), neuroendocrine tumors (two), lymphomas (two), and desmoplastic tumor (one). Patients had received a median (range) of five (1 to 14) 
prior systemic regimens and a median (range) of two (0 to 6) prior targeted agents.

Tumor suppressor gene immunohistochemistry scores versus time from last therapy

Comparing patients undergoing pre-decitabine tumor biopsy $\leq 3$ months after last prior chemotherapy or targeted therapy to those undergoing initial biopsy $>3$ months after last therapy are presented, PTEN scores were significantly higher in patients with longer time intervals since last treatment $(P=0.007)$, and there was a trend towards higher FUS1 scores in later biopsies $(P=0.15)$, while there was no association of FHIT and WWOX scores with time from last treatment.

\section{Tumor suppressor gene immunohistochemistry scores} versus LINE-1 methylation

Tumor suppressor gene scores did not correlate significantly with LINE-1 methylation in pre-decitabine tumor samples, nor in pre-and post-decitabine samples combined (Table 1). However, if pre-decitabine scores for FHIT, FUS1 and WWOX were considered together, tumors with IHC scores $=0$ for one of these genes (eight observations) had significantly higher LINE-1 methylation than did tumors with IHC scores $>0$ (58 observations) (median $61.6 \%$ versus $45.4 \%, P=0.0481$ ).

\section{Decitabine effect on tumor suppressor gene immunohistochemistry scores}

For tumors with initially low tumor suppressor gene IHC expression (scores $\leq 150$ ), expression was higher postdecitabine than pre-decitabine for FHIT $(P=0.0140)$, with a trend to higher expression post-decitabine for WWOX $(P=0.0547)$ and FUS1 $(P=0.0726)$, and little effect for PTEN $(P=0.2034)$ (Table 2, Figure 1$)$. Overall, for predecitabine scores of $\leq 150$, there was an increase in the score post-decitabine in 8 of 8 cases for FHIT, 7 of 17 for WWOX, 7 of 12 for FUS1, but only 1 of 16 for PTEN. The proportion of cases with a post-decitabine increase was significantly higher for FHIT, WWOX and FUS1 combined than for PTEN ( $P=0.003$ by Fisher's exact test). If FHIT, WWOX and FUS1 were considered together then, for cases with initial scores $\leq 150$, the median

Table 1 Correlation of tumor suppressor gene encoded proteins with LINE-1 methylation (pre- and post-decitabine)

\begin{tabular}{llll}
\hline Protein & $\mathbf{n}$ & Spearman $\mathbf{r}$ & $\boldsymbol{P}$ \\
\hline FHIT & 41 & -0.23 & 0.15 \\
WWOX & 44 & 0.09 & 0.57 \\
FUS1 & 41 & 0.15 & 0.35 \\
PTEN & 40 & 0.03 & 0.83 \\
\hline
\end{tabular}

FHIT, fragile histidine triad; FUS1, fused in sarcoma-1; LINE-1, long interspersed nuclear element-1; PTEN, phosphatase and tensin homolog; WWOX, WW domain-containing oxidoreductase. scores pre- and post-decitabine were 60 and 100, respectively $(P=0.0002)$.

Of those tumors that initially stained negatively for a tumor suppressor gene (pre-decitabine score $=0$ ), there was conversion to positive staining post-decitabine for FHIT in 1 of 1 patients, for WWOX in 3 of 6 patients, for FUS1 in 2 of 3 patients, and for PTEN in 1 of 10 patients.

\section{Post-decitabine changes in tumor suppressor gene immunohistochemistry scores versus percentage changes in LINE-1 DNA methylation}

While there was a weak negative correlation between percentage change in LINE-1 methylation and IHC score for each tumor suppressor gene, this did not achieve significance (Table 3). If we only considered tumors that initially stained negatively for a gene, there was a stronger trend $(P=0.069)$ for ones that converted from negative to positive staining with decitabine to have a greater decrease in LINE-1 methylation with decitabine (median decrease of $24 \%$ in LINE-1 methylation) than for those that did not convert (median decrease in LINE-1 methylation of $6 \%)$.

\section{Tumor suppressor gene immunohistochemistry score changes and tumor regression}

Of the 25 patients included, both change in tumor size with the first cycle of therapy and change in IHC scores for all four tumor suppressor genes could be assessed in 15 patients. Of these, 10 patients had immediate tumor growth, while five patients had a reduction in tumor diameter of $0.2 \%, 2 \%, 4.7 \%, 22.1 \%$ and $33.4 \%$, respectively. Among the five with any degree of tumor regression, all five had increases in FHIT scores, three had increases in WWOX scores, three had increases in FUS1 scores, and one had an increase in PTEN score. All five had an increase in at least one tumor suppressor gene, and three had simultaneous increases in three tumor suppressor genes (including the two patients with the greatest tumor regression), compared to 2 of 10 fully evaluable patients with tumor growth who had an increase in expression of three tumor suppressor genes ( $P=0.25$ by Fisher's exact test). Median (range) number of tumor suppressor genes increasing with decitabine was three (1 to 3 ) in those with tumor regression versus two (0 to 3 ) in fully evaluable patients with tumor growth $(P=0.34)$.

\section{Discussion}

In our phase I trial of the demethylating agent decitabine we had previously reported that percentage LINE-1 DNA methylation correlated inversely with expression of the copper/platinum transporter CTR1 and the endocytosis regulator RhoA, and that decitabine treatment 
Table 2 Median tumor suppressor gene encoded protein scores post- versus pre-decitabine for patients with pre-decitabine scores $(\leq 150)$, and number of patients with an increase, no change or decrease in scores with decitabine

\begin{tabular}{|c|c|c|c|c|c|c|c|}
\hline Protein & $\mathbf{n}$ & Score pre-decitabine & Score post-decitabine & $P$ & $\begin{array}{l}\text { Number with } \\
\text { increase in score }\end{array}$ & $\begin{array}{l}\text { Number with no } \\
\text { change in score }\end{array}$ & $\begin{array}{l}\text { Number with } \\
\text { decrease in score }\end{array}$ \\
\hline FHIT & 8 & 100 & 175 & 0.014 & 8 & 0 & 0 \\
\hline WWOX & 17 & 30 & 100 & 0.05 & 7 & 8 & 2 \\
\hline FUS1 & 12 & 67.5 & 100 & 0.07 & 7 & 2 & 3 \\
\hline PTEN & 16 & 0 & 0 & 0.20 & 1 & 10 & 5 \\
\hline FHIT, WWOX or FUS1 & 37 & 60 & 100 & 0.0002 & 22 & 10 & 5 \\
\hline
\end{tabular}

FHIT, fragile histidine triad; FUS1, fused in sarcoma-1; PTEN, phosphatase and tensin homolog; WWOX, WW domain-containing oxidoreductase.

was associated with an increase in expression of CTR1, RhoA and of the folate carrier RFC1 in patients in whom expression was initially low $[8,9]$. Early phase clinical trials also suggest that addition of decitabine to a platinum agent may partially reverse platinum-resistance in advanced ovarian carcinomas [41-43]. Hence, there is interest in further exploring the role of decitabine and other demethylating agents as resistance-modulating therapies.

In this further assessment of patients included in our phase I trial of low-dose single-agent decitabine, we assessed the impact of decitabine on expression of selected tumor suppressor genes. Loss of tumor suppressor gene function through gene deletion, mutation, or silencing (through promoter hypermethylation or other means) is important in tumorigenesis, but replacing lost tumor suppressor gene function is difficult. Attempts at tumor suppressor gene replacement by adenovirus-mediated gene therapy have met with modest early indications of success [44-46], although administration has generally been by local injection or similar means, and systemic delivery to widespread metastases is challenging. However, it has recently been demonstrated that intravenous administration of the tumor suppressor gene FUS1/TUSC2 in DOTAP nanoparticles is capable of systemic delivery to disseminated disease [47], and this approach is undergoing further investigation.

Our results with decitabine suggest that demethylating agents may be capable of upregulating expression of
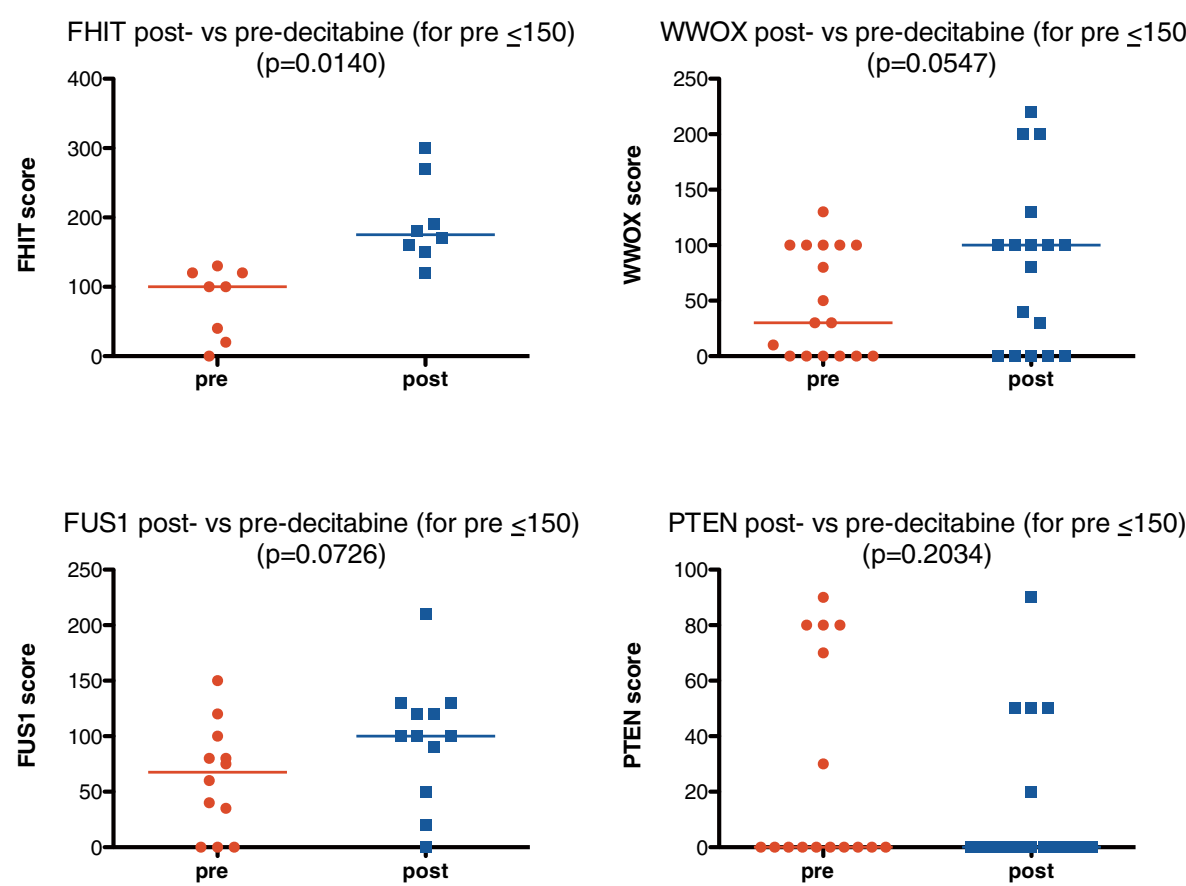

Figure 1 Change in immunohistochemistry scores for fragile histidine triad (FHIT), WW domain-containing oxidoreductase (WWOX), fused in sarcoma-1 (FUS1) and phosphatase and tensin homolog (PTEN) with decitabine for tumors with scores that were initially low ( $\leq 150)$. By Wilcoxon matched pairs signed rank tests, there was a significant increase in FHIT scores with decitabine (post- versus pre-decitabine median scores 175 versus 100, $P=0.0140$ ), with a strong trend towards an increase in WWOX (post- versus pre-decitabine median scores 100 versus 30, $P=0.0547$ ) and FUS1 (post- versus pre-decitabine median scores 100 versus $67.5, P=0.0726$ ), but with no major change in PTEN (post- versus pre-decitabine scores 0 versus $0, P=0.2034$ ). Medians are indicated by horizontal lines on the graphs. 
Table 3 Change in tumor suppressor gene encoded protein score versus percentage change in LINE-1 methylation with decitabine

\begin{tabular}{llll}
\hline Protein & $\mathbf{n}$ & Spearman $\mathbf{r}$ & $\boldsymbol{P}$ \\
\hline FHIT & 16 & -0.34 & 0.19 \\
WWOX & 19 & -0.04 & 0.87 \\
FUS1 & 16 & -0.03 & 0.91 \\
PTEN & 15 & -0.26 & 0.36 \\
Any tumor suppressor gene & 67 & -0.11 & 0.39 \\
\hline
\end{tabular}

FHIT, fragile histidine triad; FUS1, fused in sarcoma-1; PTEN, phosphatase and tensin homolog; WWOX, WW domain-containing oxidoreductase.

selected tumor suppressor genes in some patients. Low patient numbers have limited statistical power but, despite this, there was a statistically significant increase in expression of FHIT following decitabine, with a strong statistical trend towards increase in expression of WWOX and FUS1, and combining data for FHIT, WWOX and FUS1 indicated a significant increase in IHC expression of these three tumor suppressor genes together. This is sufficient to encourage further assessment of the ability of demethylating agents to restore tumor suppressor gene function in situations where it has been decreased or lost due to promoter hypermethylation. For each of these tumor suppressor genes, available published data suggest that promoter methylation may be an important cause of loss of gene function [3,4,12-17,25-27,29,48,49], although we did not have sufficient residual tissue to permit us to assess this in our study, and it is probable that other mechanisms such as gene deletion or mutation were responsible for low expression in a proportion of the tumors. We also did not have sufficient tissue available to assess whether increase in tumor suppressor gene protein expression with decitabine was associated with reduction in tumor suppressor gene DNA methylation.

There was no apparent increase in PTEN IHC scores with decitabine treatment, and changes in PTEN scores were significantly lower than changes in scores for the other tumor suppressor genes. This is in keeping with the indication from many publications that promoter methylation may not be an important cause of loss of PTEN expression [37-39], and in keeping with the hypothesis that an apparent role for PTEN promoter methylation may be due to misinterpretation of data arising from methylation of the closely related pseudogene PTENP1 [38]. An additional potential explanation for the lack of impact of decitabine on PTEN is that, for at least some genes, gene reactivation in response to decitabine requires chromatin remodeling in addition to DNA demethylation if histone modification is playing a role in gene silencing [50].

All five patients experiencing tumor regression with decitabine had an increase in the IHC score of at least one tumor suppressor gene, and three (including the two with the greatest regression) had an increase in IHC scores of three tumor suppressor genes, compared to 2 of 10 fully evaluable patients who had tumor growth who had an increase in IHC scores for three tumor suppressor genes, and the median number of tumor suppressor genes that increased with decitabine was three in patients with tumor regression versus two in patients with tumor growth. Further assessment will be needed to determine if change in tumor suppressor genes with decitabine impacts the probability of achieving tumor regression.

\section{Conclusions}

Overall, our data add further evidence that exploration of demethylating agents in solid tumors may be of interest. It may be of particular interest to explore them in tumors that are demonstrated to have low expression of tumor suppressor genes in association with promoter methylation.

\section{Methods}

This study was approved by the MD Anderson Cancer Center Research Ethics Board, and recruited consenting patients with advanced malignancies, tumors that could be safely biopsied, and organ function meeting eligibility requirements [8]. Decitabine was supplied under a Collaborative and Research Development Agreement by the National Cancer Institute Division of Cancer Treatment and Diagnosis. Decitabine doses of $2.5,5$, or $10 \mathrm{mg} / \mathrm{m}^{2} /$ day on days 1 to 5 and 8 to 12 each 4 -week cycle or 15 or $20 \mathrm{mg} / \mathrm{m}^{2} /$ day on days 1 to 5 each cycle were administered over 1 hour, with filgrastim added at higher doses [8].

Tumor biopsies were performed pre-decitabine and on day 12, cycle 1 [8]. Formalin-fixed, paraffin-embedded tissue sections ( $5 \mu \mathrm{m}$ thick) were deparaffinized in Xylene (10 minutes $\times 3$ ), followed by hydration in sequenced graded alcohols (5 minutes each). Heat-induced epitope retrieval was performed in DAKO solution for 30 minutes at $121^{\circ} \mathrm{C}$, followed by 10 minutes at $90^{\circ} \mathrm{C}$ using a Decloaking chamber (Biocare, Concord, CA), followed by a 30-minute cool-down. Prior to antibody immunostaining, endogenous peroxidase activity was blocked with $3 \%$ hydrogen peroxide in methanol for 30 minutes. To block non-specific antibody binding, tissues were incubated in $10 \%$ fetal bovine serum/Tris-buffered saline with Tween 20 for 30 minutes. Primary incubation antibodies are presented in Table 4. This was followed by incubation with Envision plus labeled polymer, antirabbit-horseradish peroxidase antibody (DAKO, Carpinteria, CA) for 30 minutes at room temperature. The FUS1 protocol was as previously described [47]. Time monitoring staining development was performed with diaminobenzidine, using a reliable positive control sample. 
Table 4 Antibodies used for immunohistochemistry

\begin{tabular}{lll}
\hline Protein & Source & Dilution \\
\hline FHIT & Thermo Scientific, Waltham, MA, USA & $1: 100$ \\
WWOX & Abcam, Cambridge, MA, USA & $1: 100$ \\
FUS1 & Homemade, rabbit polyclonal & $1: 400$ \\
PTEN & Cell Signaling, Danvers, MA, USA & $1: 75$ \\
\hline
\end{tabular}

FHIT, fragile histidine triad; FUS1, fused in sarcoma-1; PTEN, phosphatase and tensin homolog; WWOX, WW domain-containing oxidoreductase.

Slides were counterstained with hematoxylin, dehydrated, cleared and mounted.

Participating pathologist MIN scored staining intensity as 0 to $3+$ and generated IHC scores of 0 to 300 by multiplying the percent of tumor cells staining by the staining intensity. For PTEN, we assessed both cytoplasmic and nuclear staining scores, but report only on the cytoplasmic scores since results were similar for the two staining sites. Change in IHC score was defined as the day 12 score minus the day 1 score.

As previously reported, the LINE-1 assay was used to define percentage of DNA CpG islands that were methylated, as a surrogate for global DNA methylation [8,51]. Change in LINE-1 methylation was defined as the day 12 value minus the day 1 value divided by the day 1 value.

While low patient numbers limited statistical power, GraphPad Prism 5.0 (GraphPad Software, San Diego, $\mathrm{CA}$ ) was used to assess non-parametric two-tailed statistics (Spearman tests for correlations, Wilcoxon signed rank tests for paired comparisons, and Mann-Whitney tests and Fisher exact tests for comparisons of two groups).

\begin{abstract}
Abbreviations
CTR1: copper transport protein-1; FHIT: fragile histidine triad; FUS1: fused in sarcoma-1; IHC: immunohistochemistry; LINE-1: long interspersed nuclear element-1; PTEN: phosphatase and tensin homolog; PTENP1: phosphatase and tensin homolog pseudogene; RFC1: reduced folate carrier-1; RhoA: Ras homolog gene family member A; TUSC2: tumor suppressor candidate 2; WWOX: WW domain-containing oxidoreductase.
\end{abstract}

\section{Competing interests}

The authors declare that they have no competing interests.

\section{Authors' contributions}

DJS designed and oversaw the overall study, analyzed the data and drafted the manuscript. MIN performed all immunohistochemistry on tumor samples. JJ assessed LINE-1 methylation of tumor samples. DH contributed to patient recruitment. SG oversaw tumor biopsies. MA contributed to WWOX studies. JPI oversaw LINE-1 methylation studies. RK oversaw patient recruitment. IIW oversaw tumor sample collection, storage, retrieval and immunohistochemistry. All authors read and approved the final manuscript.

\section{Acknowledgements}

Supported in part by NIH grants UO1 CA062461-10, R21 CA112895-01A1, Cancer Center Support Grant number 5-P30 CA16672-32, and by Department of Defense grant number W81XWH-07-1-0306. We would like to thank MD Anderson Cancer Center for making funding available for required tumor biopsies and would also like to express our appreciation for the help and support for this project that we received from the late Dr. Igor Espinoza-Delgado while he was at CTEP, NCl.

\section{Author details}

${ }^{1}$ University of Ottawa, 501 Smyth Rd, Ottawa, ON K1H 8 L6, Canada. ${ }^{2}$ The University of Texas MD Anderson Cancer Center, 1515 Holcombe Blvd, Houston, TX 77030, USA. ${ }^{3}$ Fels Institute for Cancer Research and Molecular Biology, 3307 North Broad Street, Philadelphia, PA 19140, USA. ${ }^{4}$ UT MD Anderson Cancer Center, 1808 Park Road 1C, Smithville, TX 78957, USA. ${ }^{5}$ University of California San Diego, 3855 Health Sciences Dr, La Jolla, CA 92093, USA.

Received: 3 April 2014 Accepted: 2 June 2014

Published: 3 July 2014

\section{References}

1. Oki Y, Aoki E, Issa JP: Decitabine - bedside to bench. Crit Rev Oncol Hematol 2007, 61:140-152.

2. Ghoshal K, Bai S: DNA methyltransferases as targets for cancer therapy. Drugs Today (Barc) 2007, 43:395-422.

3. Cantor JP, lliopoulos D, Rao AS, Druck T, Semba S, Han SY, McCorkell KA, Lakshman TV, Collins JE, Wachsberger P, Friedberg JS, Huebner K: Epigenetic modulation of endogenous tumor suppressor expression in lung cancer xenografts suppresses tumorigenicity. Int J Cancer 2007, 120:24-31.

4. Iliopoulos D, Fabbri M, Druck T, Qin HR, Han SY, Huebner K: Inhibition of breast cancer cell growth in vitro and in vivo: effect of restoration of Wwox expression. Clin Cancer Res 2007, 13:268-274.

5. Phuong NT, Kim SK, Lim SC, Kim HS, Kim TH, Lee KY, Ahn SG, Yoon JH, Kang KW: Role of PTEN promoter methylation in tamoxifen-resistant breast cancer cells. Breast Cancer Res Treat 2011, 130:73-83.

6. Gravina GL, Biordi L, Martella F, Flati V, Ricevuto E, Ficorella C, Tombolini V, Festuccia C: Epigenetic modulation of PTEN expression during antiandrogenic therapies in human prostate cancer. Int J Oncol 2009, 35:1133-1139

7. Issa JP, Gharibyan V, Cortes J, Jelinek J, Morris G, Verstovsek S, Talpaz M, Garcia-Manero G, Kantarjian HM: Phase II study of low-dose decitabine in patients with chronic myelogenous leukemia resistant to imatinib mesylate. J Clin Oncol 2005, 23:3948-3956.

8. Stewart DJ, Issa JP, Kurzrock R, Nunez MI, Jelinek J, Hong D, Oki Y, Guo Z, Gupta S, Wistuba II: Decitabine effect on tumor global DNA methylation and other parameters in a phase I trial in refractory solid tumors and lymphomas. Clin Cancer Res 2009, 15:3881-3888.

9. Stewart DJ, Nunez MI, Jelinek J, Hong D, Gupta S, Issa JP, Wistuba II, Kurzrock R: Decitabine impact on the endocytosis regulator RhoA, the folate carriers RFC1 and FOLR1, and the glucose transporter GLUT4 in human tumors. Clin Epigenetics 2014, 6(1):2.

10. Ishii H, Ozawa K, Furukawa Y: Alteration of the fragile histidine triad gene early in carcinogenesis: an update. J Exp Ther Oncol 2003, 3:291-296.

11. Pichiorri F, Palumbo T, Suh SS, Okamura H, Trapasso F, Ishii H, Huebner K, Croce CM: Fhit tumor suppressor: guardian of the preneoplastic genome. Future Oncol 2008, 4:815-824.

12. Zhang X, Li HM, Liu Z, Zhou G, Zhang Q, Zhang T, Zhang J, Zhang C: Loss of heterozygosity and methylation of multiple tumor suppressor genes on chromosome 3 in hepatocellular carcinoma. J Gastroenterol 2013, 48:132-143.

13. Paluszczak J, Misiak P, Wierzbicka M, Wozniak A, Baer-Dubowska W: Frequent hypermethylation of DAPK, RARbeta, MGMT, RASSF1A and FHIT in laryngeal squamous cell carcinomas and adjacent normal mucosa. Oral Oncol 2011, 47:104-107.

14. Zochbauer-Muller S, Fong KM, Maitra A, Lam S, Geradts J, Ashfaq R, Virmani AK, Milchgrub S, Gazdar AF, Minna JD: 5' CpG island methylation of the FHIT gene is correlated with loss of gene expression in lung and breast cancer. Cancer Res 2001, 61:3581-3585.

15. Ki KD, Lee SK, Tong SY, Lee JM, Song DH, Chi SG: Role of 5'-CpG island hypermethylation of the FHIT gene in cervical carcinoma. $J$ Gynecol Oncol 2008, 19:117-122.

16. Stephen JK, Chen KM, Raitanen M, Grenman S, Worsham MJ: DNA hypermethylation profiles in squamous cell carcinoma of the vulva. Int J Gynecol Pathol 2009, 28:63-75. 
17. Kvasha S, Gordiyuk V, Kondratov A, Ugryn D, Zgonnyk YM, Rynditch AV, Vozianov AF: Hypermethylation of the $5^{\prime} \mathrm{CpG}$ island of the FHIT gene in clear cell renal carcinomas. Cancer Lett 2008, 265:250-257.

18. Nunez MI, Ludes-Meyers J, Abba MC, Kil H, Abbey NW, Page RE, Sahin A, Klein-Szanto AJ, Aldaz CM: Frequent loss of WWOX expression in breast cancer: correlation with estrogen receptor status. Breast Cancer Res Treat 2005, 89:99-105

19. Cui Z, Lin D, Cheng F, Luo L, Kong L, Xu J, Hu J, Lan F: The role of the WWOX gene in leukemia and its mechanisms of action. Oncol Rep 2013 29:2154-2162.

20. Dayan S, O'Keefe LV, Choo A, Richards Rl: Common chromosomal fragile site FRA16D tumor suppressor WWOX gene expression and metabolic reprograming in cells. Genes Chromosomes Cancer 2013, 52:823-831.

21. Aqeilan Rl, Croce CM: WWOX in biological control and tumorigenesis. J Cell Physiol 2007, 212:307-310.

22. Nunez MI, Ludes-Meyers J, Aldaz CM: WWOX protein expression in normal human tissues. J Mol Histol 2006, 37:115-125.

23. Nunez MI, Rosen DG, Ludes-Meyers JH, Abba MC, Kil H, Page R, Klein-Szanto AJ, Godwin AK, Liu J, Mills GB, Aldaz CM: WWOX protein expression varies among ovarian carcinoma histotypes and correlates with less favorable outcome. BMC Cancer 2005, 5:64.

24. Yang W, Cui S, Ma J, Lu Q, Kong C, Liu T, Sun Z: Cigarette smoking extract causes hypermethylation and inactivation of WWOX gene in T-24 human bladder cancer cells. Neoplasma 2012, 59:216-223.

25. Guo W, Wang G, Dong Y, Guo Y, Kuang G, Dong Z: Decreased expression of WWOX in the development of esophageal squamous cell carcinoma. Mol Carcinog 2013, 52:265-274.

26. Pluciennik E, Nowakowska M, Wujcicka WI, Sitkiewicz A, Kazanowska B, Zielińska E, Bednarek AK: Genetic alterations of WWOX in Wilms' tumor are involved in its carcinogenesis. Oncol Rep 2012, 28:1417-1422.

27. Baykara O, Demirkaya A, Kaynak K, Tanju S, Toker A, Buyru N: WWOX gene may contribute to progression of non-small-cell lung cancer (NSCLC). Tumour Biol 2010, 31:315-320.

28. Ji L, Roth JA: Tumor suppressor FUS1 signaling pathway. J Thorac Oncol 2008, 3:327-330

29. Demokan S, Chuang AY, Chang X, Khan T, Smith IM, Pattani KM, Dasgupta S, Begum S, Khan Z, Liegeois NJ, Westra WH, Sidransky D, Koch W, Califano JA: Identification of guanine nucleotide-binding protein gamma-7 as an epigenetically silenced gene in head and neck cancer by gene expression profiling. Int J Oncol 2013, 42:1427-1436.

30. da Costa PE, Cavalli LR, Rainho CA: Evidence of epigenetic regulation of the tumor suppressor gene cluster flanking RASSF1 in breast cancer cell lines. Epigenetics 2011, 6:1413-1424.

31. Hollander MC, Blumenthal GM, Dennis PA: PTEN loss in the continuum of common cancers, rare syndromes and mouse models. Nat Rev Cancer 2011, 11:289-301.

32. Yin L, Cai WJ, Liu CX, Chen YZ, Hu JM, Jiang JF, Li HA, Cui XB, Chang XY, Zhang WJ, Sun K, Li F: Analysis of PTEN methylation patterns in soft tissue sarcomas by MassARRAY spectrometry. PLoS One 2013, 8:e62971.

33. Kuo LT, Kuo KT, Lee MJ, Wei CC, Scaravilli F, Tsai JC, Tseng HM, Kuo MF, Tu YK: Correlation among pathology, genetic and epigenetic profiles, and clinical outcome in oligodendroglial tumors. Int J Cancer 2009, 124:2872-2879.

34. Shetty PJ, Pasupuleti N, Chava S, Nasaruddin K, Hasan Q: Altered transcription and expression of PTEN in breast tumors: is it regulated by hypermethylation? Breast Dis 2011, 33:27-33.

35. Yang HJ, Liu WW, Wang Y, Tsang PC, Ngan HY: Differential DNA methylation profiles in gynecological cancers and correlation with clinico-pathological data. BMC Cancer 2006, 6:212

36. Schondorf T, Ebert MP, Hoffmann J, Becker M, Moser N, Pur S, Göhring UJ, Weisshaar MP: Hypermethylation of the PTEN gene in ovarian cancer cell lines. Cancer Lett 2004, 207:215-220.

37. Kawaguchi K, Oda Y, Saito T, Takahira T, Yamamoto H, Tamiya S, Iwamoto Y, Tsuneyoshi M: Genetic and epigenetic alterations of the PTEN gene in soft tissue sarcomas. Hum Pathol 2005, 36:357-363.

38. Hesson LB, Packham D, Pontzer E, Funchain P, Eng C, Ward RL: A reinvestigation of somatic hypermethylation at the PTEN CpG island in cancer cell lines. Biological Procedures Online 2012, 14:5.

39. Yu J, Ni M, Xu J, Zhang H, Gao B, Gu J, Chen J, Zhang L, Wu M, Zhen S, Zhu $\mathrm{J}$ : Methylation profiling of twenty promoter- $\mathrm{CpG}$ islands of genes which may contribute to hepatocellular carcinogenesis. BMC Cancer 2002, 2:29.
40. Tamura G: Promoter methylation status of tumor suppressor and tumor-related genes in neoplastic and non-neoplastic gastric epithelia. Histol Histopathol 2004, 19:221-228.

41. Matei D, Fang F, Shen C, Schilder J, Arnold A, Zeng Y, Berry WA, Huang T, Nephew KP: Epigenetic resensitization to platinum in ovarian cancer. Cancer Res 2012, 72:2197-2205.

42. Fu S, Hu W, lyer R, Kavanagh JJ, Coleman RL, Levenback CF, Sood AK, Wolf JK, Gershenson DM, Markman M, Hennessy BT, Kurzrock R, Bast RC Jr: Phase 1b-2a study to reverse platinum resistance through use of a hypomethylating agent, azacitidine, in patients with platinum-resistant or platinum-refractory epithelial ovarian cancer. Cancer 2011, 117:1661-1669.

43. Fang F, Balch C, Schilder J, Breen T, Zhang S, Shen C, Li L, Kulesavage C, Snyder AJ, Nephew KP, Matei DE: A phase 1 and pharmacodynamic study of decitabine in combination with carboplatin in patients with recurrent, platinum-resistant, epithelial ovarian cancer. Cancer 2010, 116:4043-4053.

44. Guan YS, Liu Y, He Q, Li X, Yang L, Hu Y, La Z: p53 gene therapy in combination with transcatheter arterial chemoembolization for HCC: one-year follow-up. World J Gastroenterol 2011, 17:2143-2149.

45. Swisher SG, Roth JA, Nemunaitis J, Lawrence DD, Kemp BL, Carrasco CH, Connors DG, El-Naggar AK, Fossella F, Glisson BS, Hong WK, Khuri FR, Kurie JM, Lee JJ, Lee JS, Mack M, Merritt JA, Nguyen DM, Nesbitt JC, Perez-Soler R, Pisters KM, Putnam JB Jr, Richli WR, Savin M, Schrump DS, Shin DM, Shulkin A, Walsh GL, Wait J, Weill D, Waugh MK: Adenovirus-mediated p53 gene transfer in advanced non-small-cell lung cancer. J Natl Cancer Inst 1999, 91:763-771.

46. Clayman GL, El-Naggar AK, Lippman SM, Henderson YC, Frederick M, Merritt JA, Zumstein LA, Timmons TM, Liu TJ, Ginsberg L, Roth JA, Hong WK, Bruso $\mathrm{P}$, Goepfert H: Adenovirus-mediated p53 gene transfer in patients with advanced recurrent head and neck squamous cell carcinoma. J Clin Oncol 1998, 16:2221-2232.

47. Lu C, Stewart DJ, Lee JJ, Ji L, Ramesh R, Jayachandran G, Nunez MI, Wistuba II, Erasmus JJ, Hicks ME, Grimm EA, Reuben JM, Baladandayuthapani V, Templeton NS, McMannis JD, Roth JA: Phase I clinical trial of systemically administered TUSC2(FUS1)-nanoparticles mediating functional gene transfer in humans. PLoS One 2012, 7:e34833.

48. Li W, Deng J, Jiang P, Tang J: Association of $5^{\prime}-\mathrm{CpG}$ island hypermethylation of the FHIT gene with lung cancer in southern-central Chinese population. Cancer Biol Ther 2010, 10:997-1000.

49. Kim JS, Kim JW, Han J, Shim YM, Park J, Kim DH: Cohypermethylation of p16 and FHIT promoters as a prognostic factor of recurrence in surgically resected stage I non-small cell lung cancer. Cancer Res 2006 66:4049-4054

50. Si J, Boumber YA, Shu J, Qin T, Ahmed S, He R, Jelinek J, Issa JP: Chromatin remodeling is required for gene reactivation after decitabine-mediated DNA hypomethylation. Cancer Res 2010, 70:6968-6977.

51. Yang AS, Estecio MR, Doshi K, Kondo Y, Tajara EH, Issa JP: A simple method for estimating global DNA methylation using bisulfite PCR of repetitive DNA elements. Nucleic Acids Res 2004, 32:e38.

doi:10.1186/1868-7083-6-13

Cite this article as: Stewart et al:: Impact of decitabine on immunohistochemistry expression of the putative tumor suppressor genes FHIT, WWOX, FUS1 and PTEN in clinical tumor samples. Clinical Epigenetics 2014 6:13

\section{Submit your next manuscript to BioMed Central and take full advantage of:}

- Convenient online submission

- Thorough peer review

- No space constraints or color figure charges

- Immediate publication on acceptance

- Inclusion in PubMed, CAS, Scopus and Google Scholar

- Research which is freely available for redistribution 